DOI: $10.12731 / 2218-7405-2018-10-65-76$

УДК 159.922.7

\title{
ПСИХОЛОГИЧЕСКИЕ ОСОБЕННОСТИ РАЗНЫХ ФОРМ АГРЕССИВНОГО ПОВЕДЕНИЯ У МЛАДШИХ ШКОЛЬНИКОВ
}

\section{Леонтьева М.Д., Николаева О.Н.}

В статье представлены результаты исследования агрессивного поведения детей младшего школьного возраста. Целью работь является анализ психологических особенностей разных форм проявления агрессии.

На первой стадии были сформированы три группы агрессивных детей с различной мотивацией агрессивного поведения: импульсивно-демонстративный тип, нормативно-инструментальный и целенаправленно-враждебный типы. Установлено, что детям с импульсивно-демонстративной формой агрессии характерна высокая тревожность и негативные отношения с родителями и сиблингами.

Между тем, повыщение эмочиональной компетентности посредством коррекционной программы, позволило существенно снизить уровень агрессии в этой группе. При иеленаправленновраждебном типе агрессии детям присущи низкая социальная приспособленность и негативное самоотномение. Эта форма поведения наиболее устойчива и требует длительной коррекции. Для детей с нормативно-инструментальной формой агрессия является не механизмом защиты, а своеобразной нормой поведения. Полученные выводы могут быть использованы в профессиональной деятельности педагогов, школьных психологов, сочиильных педагогов и других специалистов системы образования.

Ключевые слова: агрессия; мотивация агрессии; межличностные отношения; эмоциональная компетентность; младший школьный возраст. 


\section{PSYCHOLOGICAL FEATURES OF VARIOUS FORMS OF AGGRESSIVE BEHAVIOR AMONG PRIMARY SCHOOL AGE CHILDREN}

\section{Leonteva M.D., Nikolaeva O.N.}

The article presents the results of a study of the aggressive behavior of children of primary school age. The aim of the work is to analyze the psychological characteristics of various forms of manifestation of aggression. At the first stage, three groups of aggressive children were formed with different motives for aggressive behavior: an impulsive demonstrative type, a normative-instrumental type, and a consciously hostile type. It was found that children with an impulsive demonstrative form of aggression are characterized by high anxiety and negative relationships with parents.

However, the increase in emotional competence through a correctional program, has significantly reduced the level of aggression in this group. With a deliberately hostile type, children have low social adaptability and negative self-attitude. This form of behavior is the most stable and requires long-term correction. For children with a normative-instrumental form, aggression is not a defense mechanism, but a peculiar norm of behavior. The findings can be used in the professional activities of teachers, school psychologists, social teachers and other specialists in the education

Keywords: aggression; motivation of aggression; interpersonal relationships; emotional competence; junior school age.

Проблема агрессивности традиционно находится в поле зрения ученых и практиков. В настоящее время одной из актуальных социальных тем, которая периодически отражается в разных средствах массовой информации, является подростковая агрессия. Однако упускается из виду, что в зоне риска находятся не только подростки, но и дети младшего школьного возраста. Проблеме агрессивного поведения младших школьников посвящено немало исследований 
(Г.Э. Бреслав, И.В. Вачков, Е.В. Гребенкин, Н.А. Дубинко, С.Н. Еникопонов, Т.Б. Миловидова, Г. Парено, А.А. Реан, Л.С. Славина, Е.О. Смирнова, И.А. Фурманов, С.Ю. Чижова и др.). Тем не менее, теоретический анализ показывает отсутствие терминологического единства, недостаточность диагностического инструментария, и поэтому проблема коррекции детской агрессии далека от своего разрешения.

Агрессивность в младшем школьном возрасте нарушает процесс благоприятной социализации личности. Эффективная психолого-педагогическая коррекция агрессивного поведения в младшем школьном возрасте является отличной профилактикой девиантности в подростковом возрасте. В данной статье мы не будем углубляться в проблему определения понятия «агрессия». Отметим, что под «агрессией» мы понимаем форму поведения, вследствие которой агрессор осознанно или неосознанно причиняет физический или моральный вред другому, не желающему подобного обращения, лицу или замещающему его предмет. В своем исследовании мы использовали классификацию детской агрессивности на основе ее движущей мотивации, если в одном случае таковой будет демонстрация себя, то в другом - достижение своих практических целей, в третьем - подавление и унижение другого. Соответственно, выделяют следующие три формы: импульсивно-демонстративная, нормативно-инструментальная и целенаправленно-враждебная [1,7].

Для успешной психолого-педагогической работы и коррекции агрессивного поведения детей важно дифференцировать формы агрессивного поведения, целесообразно учитывать особенности психологического содержания разных форм проявления агрессии. Исследование различных форм проявления агрессии и их социально-психологических детерминант представляется актуальным и практически значимым, это и является целью нашего исследования.

В исследовании приняли участие 98 детей первых классов общеобразовательной школы. 


\section{Материалы и методы исследования}

На первом этапе исследования для определения уровня агрессии и форм агрессивного поведения использовались следующие методы:

Проективная рисуночная методика «Кактус» Панфиловой М.А. [5], анкеты для учителя «Выявление форм агрессии у младших школьников» и «Признаки агрессивности» [2], наблюдение (во время учебной деятельности и в ситуациях взаимодействия со сверстниками). Наблюдение проводилось по следующим показателям: вегетативные признаки и внешние проявления агрессии; чувствительность к помощи взрослого; отношение к собственным проявлениям агрессии; недостаточность в проявлении гуманных чувств; проявлении агрессии, направленной на других детей; проявление агрессии, направленной на взрослых; проявления вербальной агрессии; проявления физической агрессии.

На втором этапе проводилось исследование психологических особенностей форм агрессивного поведения:

Проективная методика «Межличностные отношения ребенка» Рене Жиля [6]. Данная методика позволяет изучить социальную приспособленность ребенка, а также особенности его взаимоотношений с окружающими, в частности с членами своей семьи.

Цветовой тест отношений (ЦТО) А.М. Эткинда [6]. Это экспериментальная проективная методика, применяемая для диагностики характера отношений детей со значимыми для них людьми (родителями, сверстниками) а также с собственным «Я».

Проективная методика оценки уровня тревожности «Выбери нужное лицо» Р. Тэммела, М. Дорки, В. Амена [6].

\section{Результаты исследования и их обсуждение}

На первом этапе исследования совокупность результатов методики «Кактус», анкет и наблюдения позволила распределить детей по следующим группам, представленным в таблице 1:

По всей выборке большинству детей характерна импульсивнодемонстративная форма агрессии. Их агрессия носит непроизвольный, непосредственный и импульсивный характер, враждебные 
действия быстро сменяются дружелюбными, а выпады против сверстников - готовностью сотрудничать с ними. Действия детей отличаются ситуативностью, а наиболее яркие эмоции наблюдаются в момент самих действий и быстро угасают. Возможно, данный факт можно объяснить тем, что у младших школьников в силу возраста недостаточно развита произвольность и саморегуляция.

\begin{tabular}{|c|c|c|c|}
\hline $\begin{array}{c}\text { Уровень } \\
\text { агрессивности }\end{array}$ & \multicolumn{3}{|c|}{ Формы агрессивного поведения } \\
\hline & $\begin{array}{c}\text { Импульсивно- } \\
\text { демонстративная } \\
\text { форма агрессии }\end{array}$ & $\begin{array}{c}\text { Нормативно- } \\
\text { инструментальная } \\
\text { форма агрессии. }\end{array}$ & $\begin{array}{c}\text { Целенаправленно- } \\
\text { враждебная форма } \\
\text { агрессии }\end{array}$ \\
\hline Низкий уровень & $54 \%$ & $20 \%$ & $26 \%$ \\
\hline Средний уровень & $52 \%$ & $24 \%$ & $24 \%$ \\
\hline Высокий уровень & $50 \%$ & $21 \%$ & $29 \%$ \\
\hline
\end{tabular}

Нормативно-инструментальная агрессия требует более высокого уровня целенаправленности поведения. Деятельность этих детей отличается целенаправленностью и самостоятельностью. При этом они всегда стремятся к лидирующим позициям, подчиняя и подавляя других. Закономерно, что таких будет меньше в выборке.

Настораживает достаточно высокий процент детей с целенаправленно-враждебной формой агрессии. Сюда относятся дети, для которых нанесение вреда другому выступает как самоцель. Их агрессивные действия не имеют какой-либо видимой цели - ни для окружающих, ни для них самих. Они испытывают удовольствие от самих действий, приносящих боль и унижение сверстникам.

Следует отметить, что дети со средним и низким уровнем агрессивности достаточно редко проявляют физическую и вербальную агрессии, как правило агрессия этих детей носит ответный характер. Соответственно, классификация форм агрессивного поведения в их выборке носит условный характер.

Мы предположили, что причинами высокого уровня агрессивности могут быть межличностные отношения ребенка, при этом у разных форм агрессивного поведения они будут специфичны. Кроме того, уровень тревожности тоже может варьироваться. В таблице 2 
представлено наличие статистически значимой корреляции между исследуемыми нами признаками.

Таблицча 2.

\section{Статистически значимые связи (корреляции)} между исследуемыми признаками

\begin{tabular}{|c|c|c|c|}
\hline & \begin{tabular}{|c|} 
Импульсивно- \\
демонстративная \\
форма агрессии \\
\end{tabular} & $\begin{array}{c}\text { Нормативно- } \\
\text { инструментальная } \\
\text { форма агрессии. }\end{array}$ & $\begin{array}{c}\text { Целенаправленно- } \\
\text { враждебная } \\
\text { форма агрессии }\end{array}$ \\
\hline $\begin{array}{l}\text { Негативное отношение } \\
\text { к родителям }\end{array}$ & $\begin{array}{l}\text { Прямая связь } \\
(\mathrm{p} \leq 0.05)\end{array}$ & Связь отсутствует & $\begin{array}{l}\text { Прямая связь } \\
(\mathrm{p} \leq 0.05)\end{array}$ \\
\hline $\begin{array}{l}\text { Негативное отношение } \\
\text { к братьям и сестрам }\end{array}$ & $\begin{array}{l}\text { Прямая связь } \\
(\mathrm{p} \leq 0.05)\end{array}$ & Связь отсутствует & $\begin{array}{l}\text { Связь } \\
\text { отсутствует }\end{array}$ \\
\hline $\begin{array}{l}\text { Негативное } \\
\text { отношение к учителю }\end{array}$ & $\begin{array}{l}\text { Связь } \\
\text { отсутствует }\end{array}$ & Связь отсутствует & $\begin{array}{l}\text { Связь } \\
\text { отсутствует }\end{array}$ \\
\hline $\begin{array}{l}\text { Негативное } \\
\text { отношение к отцу }\end{array}$ & $\begin{array}{l}\text { Прямая связь } \\
(\mathrm{p} \leq 0.01)\end{array}$ & Связь отсутствует & $\begin{array}{l}\text { Прямая связь } \\
(\mathrm{p} \leq 0.05)\end{array}$ \\
\hline $\begin{array}{l}\text { Негативное } \\
\text { отношение к матери }\end{array}$ & $\begin{array}{l}\text { Связь } \\
\text { отсутствует }\end{array}$ & Связь отсутствует & $\begin{array}{l}\text { Связь } \\
\text { отсутствует }\end{array}$ \\
\hline $\begin{array}{l}\text { Негативное } \\
\text { отношение к школе }\end{array}$ & $\begin{array}{l}\text { Связь } \\
\text { отсутствует }\end{array}$ & Связь отсутствует & $\begin{array}{l}\text { Прямая связь } \\
(\mathrm{p} \leq 0.05)\end{array}$ \\
\hline $\begin{array}{l}\text { Негативное } \\
\text { самоотношение }\end{array}$ & $\begin{array}{l}\text { Связь } \\
\text { отсутствует }\end{array}$ & Связь отсутствует & $\begin{array}{l}\text { Прямая связь } \\
(\mathrm{p} \leq 0.01)\end{array}$ \\
\hline Тревожность & $\begin{array}{l}\text { Прямая связь } \\
(\mathrm{p} \leq 0.01)\end{array}$ & Связь отсутствует & $\begin{array}{l}\text { Связь } \\
\text { отсутствует }\end{array}$ \\
\hline
\end{tabular}

Как и ожидалось, каждой из групп детей присущи свои особенности.

Так, группе детей с импульсивно-демонстративной формой агрессии характерно негативное отношение к братьям и сестрам, негативное отношением к родителям (особенно негативное отношение к отцу). Согласно данным психологических исследований таких детей отличает обостренная потребность во внимании и в признании со стороны родителей, но ввиду того, что другими способами обратить на себя внимание они не могут, так как не отличаются успехами в учебной или игровой деятельности, то проявляют агрессию по отношению к окружающим. При этом они получают негативное внимание, связанное с наказанием за проявленную агрессию, поэтому у них формируется негативное отношение к своим родителей. Ситуация ухудшается в семьях с сиблингами, чувство ревности к брату 
или сестре, ощущение несправедливости, исходящей от родителей и недостаток их внимания стимулируют проявления агрессии младшими школьниками. Все это повышает уровень их тревожности.

У младших школьников с нормативно-инструментальной формой агрессии нет связи с особенностями их межличностных отношений и уровнем тревожности. Агрессия детей, имеющих данную форму, обусловлена тем, что они воспринимают ее как норму поведения, а не как механизм защитной реакции, способ привлечения к себе внимания или цель нанести кому-либо вред.

В третьей группе с целенаправленно-враждебной формой агрессивного поведения обнаружилось негативное отношение к родителям (особенно к отцу), негативное отношение к школе и негативное самоотношение. При этой форме агрессивного поведения нанесение вреда другому выступает как самоцель. Негативное отношение родителей, в частности отца, воспринимаемое младшими школьниками, выливается в желание выплеснуть свои негативные эмоции, что выражается в целенаправленном совершении агрессивных действий в отношении слабых сверстников.

По причине повышенной агрессивности этих детей не принимает детский коллектив. Как следствие, младшие школьники с целенаправленно-враждебной формой агрессии закрываются в своем внутреннем мире и отгораживаются от группы сверстников. Негативные взаимоотношения с одноклассниками провоцируют негативные отношения и с учителями, как медиаторами, разрешающими возникающие между детьми конфликты. Эти дети воспринимаются одноклассниками и учителями как драчуны, от них постоянно ожидают, что они кого-либо обидят, проявляют к ним отрицательные эмоции. В результате этого у младших школьников с целенаправленно-враждебной формой агрессии возникает негативное отношение к школе.

В связи с тем, что с этими первоклассниками не проявляют желание общаться сверстники, они регулярно получают замечания от учителей и испытывают негативное отношение со стороны родителей, у них могут формироваться негативные установки по от- 
ношению к себе. Таким образом, особенности их межличностных отношений провоцируют повышение уровня агрессии и беспричинное нанесение вреда окружающим.

Результаты данного исследования хорошо коррелируют с результатами исследования взаимосвязи агрессивности с целенаправленным поведением Мавляновой О.В. [4]. В частности, Мавлянова выяснила, что у детей с высоким уровнем агрессии и высоким уровнем целенаправленности эмоциональная компетентность определяется хорошо развитыми когнитивными способностями обработки эмоционального опыта. Но таким детям сложно распознавать эмоции, у них недостаточное внимание к переживаниям другого человека, неспособность поставить себя на его место. Несомненно, что это относится к детям с нормативно-инструментальной формой агрессивного поведения.

Детей с высоким уровнем агрессии и низким уровнем целенаправленности отличают бедность словаря эмоций и затруднения в понимании эмоционального смысла ситуации. Им часто сложно понять и объяснить свое эмоциональное состояние и то, какие эмоции несет в себе значение ситуации. К этой группе мы отнесем детей с импульсивно-демонстративной и целенаправленно-враждебной формами агрессии.

Исходя из представленных результатов, дальнейшая психокоррекционная работа с детьми из разных групп имела специфические задачи. В случае с нормативно-инструментальной формой агрессии работа была направлена на повышение уровня эмпатии, на способность почувствовать другого человека. При импульсивно-демонстративной форме ставилась задача - развить когнитивные способности обработки эмоционального опыта, а при целенаправленно-враждебной агрессивности как развитие эмпатии, так и эмоциональных когнитивных навыков. Психокоррекционные программы были проведены в течение месяца, включали в себя диагностические занятия; общие занятия со всей выборкой, направленные на снижение общего уровня агрессивности; занятия по группам; консультационные и профилактические мероприятия с родителями. 
В каждой из групп младших школьников были отмечены позитивные тенденции в снижении уровня агрессии. Однако результаты математического анализа позволяют сказать, что статистически достоверные положительные сдвиги в снижении уровня агрессии у младших школьников получены в группах импульсивно-демонстративной формы агрессии и нормативно-инструментальной. В группе учеников с целенаправленно-враждебной формой проявления агрессии положительные сдвиги не являются статистически значимыми, что показано в таблице 3.

Таблица 3.

Эмпирические значения критерия Т-Вилкоксона

\begin{tabular}{|c|l|c|c|c|}
\hline № & \multicolumn{1}{|c|}{ Группа учеников } & $\begin{array}{c}\text { Значение } \\
\text { критерия } \\
\text { Т-Вилкоксона }\end{array}$ & $\begin{array}{c}\text { Область } \\
\text { значимости }\end{array}$ & $\begin{array}{c}\text { Уровень } \\
\text { значимости }\end{array}$ \\
\hline 1 & $\begin{array}{l}\text { Импульсивно- } \\
\text { демонстративная форма } \\
\text { агрессии }\end{array}$ & 10 & $\begin{array}{c}\text { Зона } \\
\text { значимости }\end{array}$ & $\begin{array}{c}\mathrm{p} \leq 0.05 \\
\left(\mathrm{~T}_{\text {Кр }}=10\right)\end{array}$ \\
\hline 2 & $\begin{array}{l}\text { Нормативно- } \\
\text { инструментальная форма } \\
\text { агрессии }\end{array}$ & $\begin{array}{l}\text { Зона } \\
\text { Значимости }\end{array}$ & $\begin{array}{c}\mathrm{p} \leq 0.05 \\
\left(\mathrm{~T}_{\mathrm{Kp}}=3\right)\end{array}$ \\
\hline феленаправленно-враждебная & 40 & $\begin{array}{c}\text { Зона не } \\
\text { значимости }\end{array}$ & $\begin{array}{c}\mathrm{p} \leq 0.05 \\
\left(\mathrm{~T}_{\mathrm{Kp}}=10\right)\end{array}$ \\
\hline
\end{tabular}

\section{Заключение}

Во-первых, наиболее распространенная форма агрессивного поведения у младших школьников - импульсивно-демонстративная. Для нее характерно негативное отношение к родителям, сиблингам, повышенная тревожность вследствие неумения выразить свои эмоции, привлечь внимание к себе другими способами. Упражнения на повышение эмоциональной компетентности и консультационная работа с родителями позволили существенно снизить уровень агрессии в течение месяца.

Во-вторых, нормативно-инструментальная агрессия отличается высоким уровнем целенаправленности, поэтому характеризуется низким уровнем эмпатии. В нашем случае, эта форма агрессии не оказалась связана с социальной приспособленностью, что доста- 
точно логично. Грамотно составленная психокоррекционная программа позволила снизить уровень агрессии с высокого уровня на средний.

В-третьих, целенаправленно-враждебная форма наиболее трудно корректируется в силу своей изначальной мотивации. Дети данной группы оказались наименее социально приспособленными, у них нарушены эмоциональные взаимоотношения как с родителями, так и со школой, отсюда негативное самоотношение, что провоцирует высокий уровень агрессии по отношению к окружающим. В этом случае необходима более содержательная работа с источниками мотивации личности, продолжительная работа с родителями. Ситуация может осложняться социальным неблагополучием семьи.

\section{Список литературы}

1. Абраменкова В.В. Справочник по психологии и психиатрии детского и подросткового возраста / В.В. Абраменкова, М.А. Белянчикова, А.Л. Битова; под ред. С.Ю. Циркин; Ассоциация детских психиатров и психологов. СПб., 2014. 896 с.

2. Астапов В.М. Психодиагностика и коррекция детей с нарушениями и отклонениями развития / В.М. Астапов, Ю.В. Микадзе. М.: Спб, Питер, 2001. 377 с.

3. Бреслав Г. Психологическая коррекция детской и подростковой агрессивности. СПб.: Речь, 2004.

4. Мавлянова О.В. Особенности эмоциональной компетентности детей младшего школьного возраста с разными формами агрессивного поведения // Психологическая наука и образование, 2010, № 4. http://psyjournals.ru/files/33676/psyedu_ru_2010_4_Mavlyanova.pdf

5. Панфилова М.А. Графическая методика «Кактус» // Обруч, № 5, 2002. C. 12-15.

6. Реан А.А. Агрессия и агрессивность личности. СПб, 1995. С. 303-347.

7. Смирнова Е.О., Хузеева Г.Р. Психологические особенности и варианты детской агрессивности // Вопросы психологии. 2002. № 1. C. $17-25$. 


\section{References}

1. Abramenkova V.V., Belyanchikova M.A., Bitova A.L. Spravochnikpo psihologii I psihiatrii detskogo I podrostkovogo vozrasta [Handbook on the psychology and psychiatry of children and adolescents]. SPb., 2014.

2. Astapov V.M., Mikadze U.V. Psihodiagnostika i korreksia detei s narusheniami I otkloneniiami razvitiia [Psychodiagnostics and correction of children with impaired and developmental disabilities]. SPb., 2001.

3. Breslav G.M. Psikhologicheskaya korrektsiya detskoy i podrostkovoy agressivnosti [Psychological correction of child and adolescent aggression]. M., 2004.

4. Mavlianova O.V. Psochologicheskaia nauka i obrazovaniie, 2010, no 4. http://psyjournals.ru/files/33676/psyedu_ru_2010_4_Mavlyanova.pdf

5. Panfilova M.A. Graficheskaia metodika 'Kaktus' [Graphic technique "Cactus"]. Obruch, 2002, №5.

6. Rean A.A. Agressia i agressivnost lichnosti [Aggression and aggressiveness of the individual]. SPb., 1995, pp. 303-347.

7. Smirnova E.O., Huzeeva G.R. Psihologicheskie osobennosti i variant detskoi agressivnosti [Psychological features and variants of children's aggressiveness].Voprosy psihologii, 2002, no 1, pp. 17-25.

\section{ДАННЫЕ ОБ АВТОРАХ}

Леонтьева Мария Дмитриевна, доцент, кандидат психологических наук

Северо-Восточный федеральный университет ул. Белинского, 58, г. Якутск, Республика Саха (Якутия), 677000 , Российская Федерациия maribu_7@mail.ru

Николаева Ольга Николаевна, магистр Института психологии Северо-Восточный федеральный университет ул. Белинского, 58, г. Якутск, Республика Саха (Якутия), 677000, Российская Федерациия taina90@bk.ru 


\section{DATA ABOUT THE AUTHORS}

Leonteva Maria Dmitrievna, Associate of Professor, $\mathrm{PhD}$

North-Eastern Federal University

58, Belinsky Str., Yakutsk, Republic of Sakha (Yakutia), 677000, Russian Federation

maribu_7@mail.ru

Nikolaeva Olga Nikolaevna, Master of Psychology and Social Sciences Chair, Institute of Psychology

North-Eastern Federal University

58, Belinsky Str., Yakutsk, Republic of Sakha (Yakutia), 677000, Russian Federation

taina90@bk.ru 